\title{
Main prognostic and predictive immunohistochemical factors in breast cancer: a retrospective cohort study
}

\author{
Diogo Ferreira Ducatti* (i), Cláudio Galleano Zettler ${ }^{1}$ (i)
}

\section{ABSTRACT}

Introduction: Breast cancer is a constant focus of studies on prevention and treatment. Immunohistochemistry is a useful tool for defining the conducts toward the treatment of this disease. Objective: To evaluate patients' survival according to prognostic and predictive immunohistochemical factors. Method: This is a retrospective cohort study. Medical reports of 787 patients were analyzed, which contained parts of surgical specimens of the mastectomy or quadrantectomy procedures. A total of 404 patients were eligible for the study. Results: The mean age at diagnosis of the disease was 55.4 years. The main diagnosis was infiltrating ductal carcinoma (80.7\%). Of the total, $45 \%$ of the patients had tumors of up to $2 \mathrm{~cm}$ in diameter, and $32.9 \%$ had lymph node involvement. Among the patients, and according to luminal molecular classification, $48.3 \%$ were classified as luminal A, 27\% were luminal B, 12.1\% were recipient of human epidermal growth factor type 2 (HER2), and 12.6\% were triple-negative. Furthermore, of 23.3\% patients with tumor recurrence, $12.6 \%$ of them died. The $1 \%$ increase in Ki-67 values increases the risk of death and recurrence by $2 \%$ and $1 \%$, respectively. The presence of lymph node metastasis increases, on average, 4.78 times and 2.63 times the risk of death and recurrence, respectively. Conclusion: The triple negative molecular classification had the lowest overall survival and the greatest risk of recurrence. The luminal A classification presented the best prognosis. Tumor size, lymph node metastasis, skin invasion, and presence of Ki-67 were shown to be the prognostic and predictive factors that most influenced the patients' survival.

KEYWORDS: breast cancer; immunohistochemistry; prognosis; survival; recurrence.

\section{INTRODUCTION}

Breast cancer is the most common malignant neoplasm found in Southern Brazil, with the exception of non-melanoma skin cancer. In 2018 alone, there were 56.33 cases per 100,000 women, which corresponds to more than $20 \%$ of all types of cancer'.

Breast cancer is the leading cause of death among women worldwide, accounting for 522,000 deaths in 2012 alone, equivalent to $14.7 \%$ of all deaths in that year. The incidence of breast cancer has virtually increased worldwide, but in developed countries, this number has decreased in the last 10 years. Moreover, there has been a reduction in the death rate related to breast cancer due to adequate screening, early detection, and effective therapy ${ }^{2}$.

Breast neoplasm does not indicate clinical uniformity and is characterized according to the morphology of the disease, thus existing different molecular forms and subtypes. Instead, it should be stated that breast cancer consists of a range of distinct neoplasms, which are all classified as breast cancer. These varied forms of the disease enable the evaluation and development of prognosis based on their evolution, making it possible to prescribe specific treatments according to the development and characteristics of each type. Acknowledging this is important due to the need for defining the prognosis and the appropriate approach, aiming at avoiding to unnecessarily submit patients to aggressive treatments such as chemotherapy ${ }^{3}$.

Immunohistochemical examination and anatomopathological analysis are paramount to define the disease approach and the prognosis of the patient. Immunohistochemistry is a technique used to identify biological characteristics of tumors, including breast-related ones. Molecular technology with biomarkers allows identifying and classifying breast cancer into different subtypes that, consequently, exhibit different behaviors. Biomarkers are often used for determining the best therapy to be provided and

'Universidade Federal de Ciências da Saúde de Porto Alegre - Porto Alegre (RS), Brazil.

*Corresponding author: diogoducatti@hotmail.com

Conflict of interest: nothing to declare.

Received on: 10/16/2019. Accepted on: 12/25/2019 
for other decisions concerning treatment approaches, including the confirmation of metastases. This technology has proved to be an important diagnosis tool, since it is a simple, practical, and versatile instrument ${ }^{4}$.

\section{PROGNOSTIC FACTORS}

Prognostic factors consist of aspects that may interfere with the clinical evolution of the disease at the time of diagnosis. The main parameters for determining the therapeutic planning of breast cancer are age, tumor size, lymph node involvement, and molecular subtype ${ }^{5}$.

Age is among the three main prognostic factors that are prominent when it comes to survival in breast cancer. It carries a considerable weight to decisions to be made at two moments during the course of the disease: first, at diagnosis and, secondly, at the definition of the treatment to be provided, being older age directly related to the worst outcome of breast cancer. ${ }^{6}$ Older women and those in menopause have fewer recurrences and deaths from breast cancer, usually because they feature less aggressive molecular classification, though they are affected by age-related issues, and the presence of aging-related comorbidities, which limit therapies or their responses, are common. Conversely, younger women develop larger tumors, high histologic grade, increased vascular invasion, and lymph node involvement, even when submitted to more aggressive treatments ${ }^{7-9}$.

Tumor size has key importance in the survival of breast cancer patients. Survival is proportionally inferior to tumor size. That is, tumors with larger diameters are associated with lymph node involvement, higher mortality, and lower disease-free survival ${ }^{8-12}$.

Breast tumors manifest responses to the provided therapies and disease evolution in a very varied way. This is because breast tumors have complex genome variation. These variations allow such tumors to present very different evolutions and biological behaviors, although they are all classified as breast cancer. Molecular classification allows identifying, with a high degree of accuracy, different types of the disease based on profiles. Thus, if a metastasis, whether distant or in a lymph node, is related to a certain tumor, it will present the same pattern of genes as if it were a sample of the main tumor ${ }^{13}$.

\section{PREDICTIVE FACTORS}

Lymph node involvement is the predictive factor that mostly influences therapeutic approaches. Based on this involvement, the breast volume that will be exposed to radiation in radiotherapy treatment can determine, in addition to whether there shall be lymph node clearance of the axillary region, which can cause important side and aesthetic effects on the quality of life of patients under treatment ${ }^{14}$. This factor greatly influences the outcome of breast cancer, especially when there is involvement of axillary lymph nodes, since they have a strong impact on overall survival and disease-free survival in a 10 -year period ${ }^{8,9}$. Lymph node involvement indicates that, in addition to breast cancer being aggressive, it is already in a dimension that will interfere with disease-free and overall survival rates, regardless of the provided therapy ${ }^{15}$.

Hence, lymph node invasion is a predictive factor for metastatic dissemination of breast cancer, contributing to a worsened evolution of the disease ${ }^{16}$.

The most commonly used biomarkers in determining the treatment for breast cancer are estrogen and progesterone hormone receptors ${ }^{17}$.

The human epidermal growth factor receptor type 2 (HER2) performs specific functions of cell differentiation, regulation, and proliferation. Its overexpression occurs in $15 \%$ of breast tumors. Mostly, it features negative hormone receptors and is related to a more aggressive type of the disease and worse prognosis. Its advantage is the current existence of target molecular therapy for tumors manifesting this overexpressed factor ${ }^{18,19}$.

The Ki-67 proliferation index indicates cell multiplication. It is present in all active phases of the cell cycle, with the exception of the $\mathrm{G} 0$ phase ${ }^{20}$, being routinely evaluated in immunohistochemical tests for breast cancer as it is responsible for the differentiation between tumors of luminal types A and B. Ki-67 is directly associated with tumor aggressiveness and poor progno$\operatorname{sis}^{21}$. It represents high histologic grade and high speed of tumor growth, providing reliable, easy-to-analyze, and low-cost information, being paramount for determining the clinical conduct ${ }^{22}$.

Breast tumor cells have many structural differences, even when they are very similar according to microscope images. Immunophenotyping allowed the creation of gene expression profiling, which can be used to identify tumor evolution based on its molecular phenotype ${ }^{7}$.

The aim of this study was to compare the main pathological prognostic and predictive factors with the outcome of patients who underwent treatments for breast carcinoma. Disease-free survival time was related to prognostic factors of tumor size, age, and lymph node involvement; in addition, disease-free survival time according to predictive factors of molecular classification by immunophenotyping were evaluated.

\section{METHODOLOGY}

A survey on all female patients who had their surgical specimens of breast carcinoma analyzed in the Pathology Laboratory of Hospital Santa Rita da Irmandade da Santa-Casa de Misericórdia de Porto Alegre (ISCMPA), from 2008 to 2012, was performed. Then, each of the medical reports were read, leading to the selection of those in which the specimens derived from a surgical procedure of mastectomy or quadrantectomy. Each of the medical reports was cataloged and transformed into a number, aiming to ensure the 
patients' anonymity. Date of diagnosis, age of the patient, size of the surgical specimen, tumor grade, immunohistochemical classification, surgical margins, lymph node involvement, presence of carcinoma in situ, date of recurrence (when is the case), and date of the last follow-up were used to import data into a spreadsheet in the Excel computer program ${ }^{\circledast}$ for the analysis.

In some cases, there were divergences between the immunohistochemical classification of the biopsy and the subsequent analysis of the surgical specimen. This is due to biopsies being performed on a small portion of the tumor. On the other hand, the surgical specimen is analyzed in the so-called "hot spot," where the highest concentration of tumor cells is found. Since it is deemed the most reliable analysis, a real classification was considered as that performed after the analysis of the specimen by the Pathology Laboratory. The deadline for updating each patient's outcome was December 31 $1^{\text {st }}, 2018$.

Death was measured and validated in the study only when it occurred within the institution and it was recorded in the electronic medical reports of each patient.

Patients who had undergone any procedure other than mastectomy or quadrantectomy, those with a history of previous neoplasms, or whose pathological examinations proved the emergence of new primary lesions were excluded from the study.

We followed the ethical precepts of Resolution No. 466/2012 of the National Health Council (Conselho Nacional de Saúde CNS), respecting the confidentiality of the participating subjects. Data were anonymously managed, without any nominal identification or other information that allowed identifying the participants.

The project was approved by the Research Ethics Committee of ISCMPA, under Opinion no. 2.324.152.

\section{STATISTICAL ANALYSIS}

Quantitative variables were described by mean and standard deviation or by median and interquartile range, and categorical variables, by absolute and relative frequencies (Table 1).

Overall survival and disease-free survival curves were estimated by the Kaplan-Meier method ${ }^{22}$ (Figures 1 and 2). To evaluate factors associated with outcomes, the univariate and the multivariate Cox proportional hazards regression models ${ }^{23}$ were applied (Table 2). All variables that presented $\mathrm{p}<0.20$ in the univariate analysis were inserted in the multivariate model (Table 3); in the final model, only variables presenting $\mathrm{p}<0.10$ remained.

The adopted significance level was $5 \%$, and analyses were performed in the Statistical Package for the Social Sciences (SPSS) program, version 21.0.

\section{RESULTS}

In total, the medical reports of 787 patients that comprised immunohistochemical and anatomopathological analyses of the mastectomy or quadrantectomy procedures were directly analyzed. After applying the eligibility criteria, the reports of 404 patients were eligible for the study. The mean age of the

Table 1. Characterization of the sample.

\begin{tabular}{|c|c|}
\hline Variables & $\mathrm{n}=404$ \\
\hline Age at diagnosis (years) - mean $\pm S D$ & $55.4 \pm 12.3$ \\
\hline Current age (years) - mean $\pm S D$ & $61.8 \pm 12.6$ \\
\hline \multicolumn{2}{|l|}{ Diagnosis - n (\%) } \\
\hline Infiltrating ductal carcinoma & $326(80.7)$ \\
\hline Infiltrating lobular carcinoma & $39(9.7)$ \\
\hline Infiltrating ductal and lobular carcinoma & $8(2.0)$ \\
\hline Carcinoma in situ & $31(7.7)$ \\
\hline \multicolumn{2}{|l|}{ Tumor size - n (\%) } \\
\hline Up to $2 \mathrm{~cm}$ in diameter & $182(45.0)$ \\
\hline Between 2 and $5 \mathrm{~cm}$ in diameter & $164(40.6)$ \\
\hline Over $5 \mathrm{~cm}$ in diameter & $29(7.2)$ \\
\hline Any tumor size with chest wall or skin invasion & $29(7.2)$ \\
\hline \multicolumn{2}{|l|}{ Histologic grade - n (\%) } \\
\hline GI & $55(13.6)$ \\
\hline GII & $204(50.6)$ \\
\hline G III & $144(35.7)$ \\
\hline \multicolumn{2}{|l|}{ Lymph nodes - n (\%) } \\
\hline Lymph node metastasis (S) & $133(32.9)$ \\
\hline No lymph node metastasis & $271(67.1)$ \\
\hline \multicolumn{2}{|l|}{ Type of surgery - n (\%) } \\
\hline Quadrantectomy & $284(70.3)$ \\
\hline Mastectomy & $120(29.7)$ \\
\hline Skin invasion - n (\%) & $24(5.9)$ \\
\hline Nipple invasion - $\mathrm{n}(\%)$ & $15(3.7)$ \\
\hline Solitary nodule - n (\%) & $352(87.1)$ \\
\hline Presence of carcinomas in situ - $n$ (\%) & $215(53.2)$ \\
\hline Tumor-free surgical margin - median (P25-P75) & $0.3(0.1-0.8)$ \\
\hline Presence of inflammatory infiltrate - $n$ (\%) & $136(33.7)$ \\
\hline Estrogen receptor - median (P25-P75) & $90(62.5-90)$ \\
\hline Progesterone receptor - median (P25-P75) & $40(0-80)$ \\
\hline HER2 $>30 \%-n(\%)$ & $50(12.4)$ \\
\hline Ki-67 - median (P25-P75) & $10(5-30)$ \\
\hline \multicolumn{2}{|l|}{ Molecular classification - n (\%) } \\
\hline Luminal A & $195(48.3)$ \\
\hline Luminal B & $109(27.0)$ \\
\hline HER2 & $49(12.1)$ \\
\hline Triple negative & $51(12.6)$ \\
\hline Death - n (\%) & $51(12.6)$ \\
\hline Recurrence - n (\%) & $94(23.3)$ \\
\hline
\end{tabular}

SD: standard deviation; HER2: human epidermal growth factor receptor type 2 . 
patients at the time of diagnosis was 55.4 years, with a standard deviation of 12.3. The mean age at the end of the analysis of the medical reports, on December 31 ${ }^{\text {st }}$, 2018, was 61.8 years, with a standard deviation of 12.6. The diagnosis of greatest predominance was infiltrating ductal carcinoma, accounting for an $80.7 \%$ occurrence, followed by infiltrating lobular carcinoma, with $9.7 \%$, and carcinoma in situ, with $7.7 \%$. Taken together, the presence of ductal carcinoma and lobular carcinoma occurred in $2 \%$ of the sample.

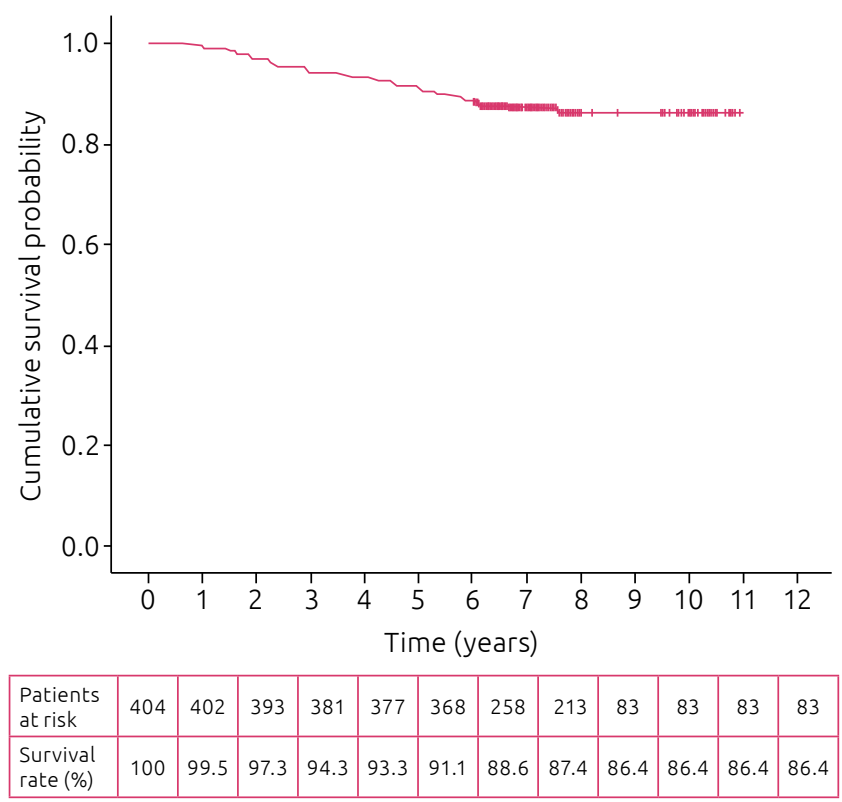

Figure 1. Survival curve according to the Kaplan-Meier method.

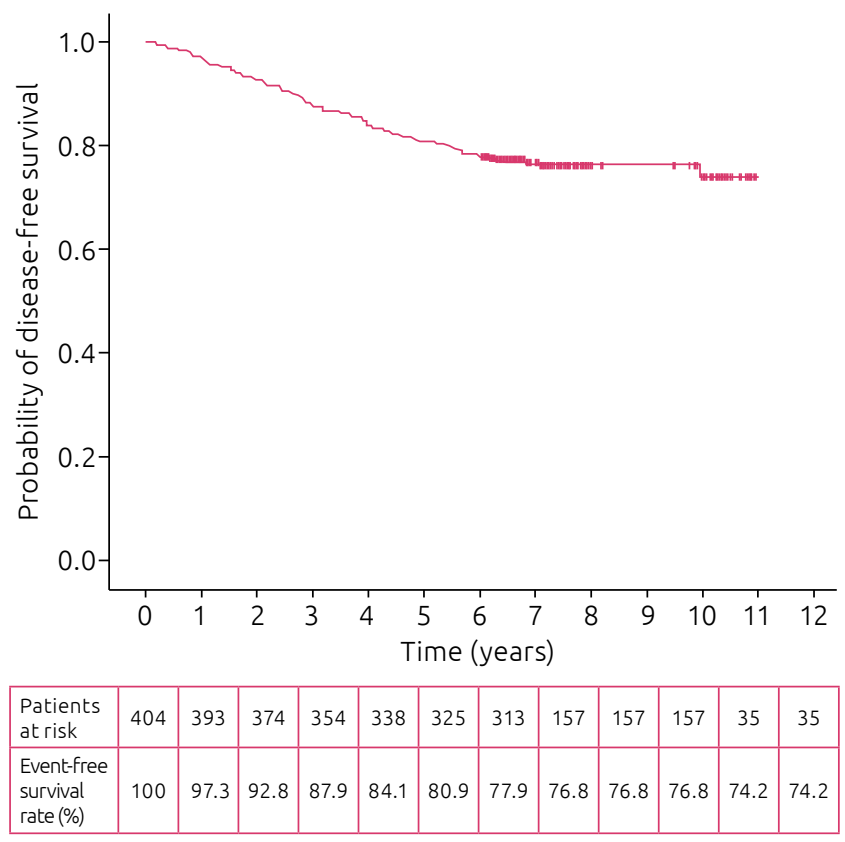

Figure 2. Disease-free survival curve according to the Kaplan-Meier method.
Variables with overall survival were associated with virtually all variables, except carcinomas in situ, tumor-free surgical margin, inflammatory infiltrate, and HER2. These same variables, in addition to the multinodal variable, were not significantly associated with disease-free survival.

To control confounding factors, the multivariate Cox regression model was performed (Table 3). After adjustment, current age, tumor size, lymph node metastasis, and Ki-67 remained associated with both overall survival and disease-free survival.

Molecular classification showed no significant relevance in the multivariate analysis.

The most frequent tumor size, according to the international classification system validated by the American Joint Committee on Cancer (AJCC) and by the Union for International Cancer Control (UICC), used as a tool in the staging of neoplasms, namely the TNM, was classified as T1, with tumors of up to $2 \mathrm{~cm}$ in diameter and occurrence of $45 \%$ in the analyses. Tumors between 2 and $5 \mathrm{~cm}$ in diameter, classified as T2, corresponded to $40.6 \%$ of the sample. Tumors classified as T3 and T4 stages corresponded to the remaining $14.4 \%$. Among tumors classified as T4, the most present invasion was the skin one, with a $5.9 \%$ occurrence. Nipple invasion had a frequency of $3.7 \%$ of the sample.

According to the histologic grading modified by Elston and Ellis ${ }^{22}$, the most frequent histologic grade was II, with $50.6 \%$, corresponding to moderately differentiated tissues; followed by grade III, with badly differentiated tissues in $35.7 \%$ of the sample; and finally grade I, with well-differentiated tissues in $13.6 \%$ of the sample. Regarding lymph node involvement, $32.9 \%$ of patients presented lymph node metastases.

The use of neoadjuvant chemotherapy and the evolution of adequate staging and surgical techniques enabled to perform much more breast-conserving surgeries in the treatment of breast cancer. Thus, the most frequent surgical procedure in the study was the quadrantectomy, corresponding to $70.3 \%$ of the surgical profile identified in the sample. In this profile, the median of $0.3 \mathrm{~cm}$ of the surgical margin was maintained. A total of $53.2 \%$ of patients presented carcinoma in situ. Inflammatory infiltrate was present in $33.7 \%$ of the analyses. When there was presence of hormonal receptors, estrogen and progesterone, they represented a median of 90 and $40 \%$, respectively. HER $2 \geq 30 \%$ occurred in $12.4 \%$ of the analyses. The Ki-67 proliferation index had a median of $10 \%$.

The most frequent molecular classification was luminal A (48.3\%), followed by luminal B (27\%), HER2, and triple-negative (both with $12.6 \%$ each). The sample accounted for $12.6 \%$ of death and a total of $23.3 \%$ of recurrences.

\section{DISCUSSION}

As described in the literature ${ }^{25}$, no statistically positive difference or evidence was found between the outcome of patients 
who underwent quadrantectomy instead of mastectomy. In this sense, patients who underwent mastectomies had 2.06 times more deaths and 1.67 times more recurrences than patients treated with breast-conserving surgeries. Surgeries for the treatment of breast cancer have developed in such a way that major mutilating surgeries are being replaced with minimal surgical resections without impacts on the patients' prognosis ${ }^{11}$.

Carcinoma in situ showed no statistical significance for the study, nor did the $33.7 \%$ of patients with inflammatory infiltrate.
In the univariate Cox regression analysis to evaluate factors, such as overall and disease-free survival rates, almost all factors were significantly associated. The mean age at the time of diagnosis was 55.4 years, which is similar to the mean of 56.8 years reported in other studies $^{8,9}$. According to the regression analysis, age was associated with a 0.95 risk of death or recurrence. According to the univariate analysis, tumors classified as $\mathrm{T} 2$ increase the possibility of death by 2.31 times, and the possibility of recurrence by 1.7 times. Tumors with more than $5 \mathrm{~cm}$ in diameter, classified as $\mathrm{T} 3$, worsen the overall and

Table 2. Univariate Cox regression analysis to evaluate factors associated with overall survival and disease-free survival.

\begin{tabular}{|c|c|c|c|c|}
\hline \multirow[b]{2}{*}{ Variables } & \multicolumn{2}{|c|}{ Overall survival } & \multicolumn{2}{|c|}{ Disease-free survival } \\
\hline & $\begin{array}{c}\text { Hazard ratio } \\
(95 \% \mathrm{Cl})\end{array}$ & $\mathbf{P}$ & $\begin{array}{l}\text { Hazard ratio } \\
(95 \% \mathrm{Cl})\end{array}$ & $\mathbf{P}$ \\
\hline Age at diagnosis (years) & $0.97(0.95-0.99)$ & 0.005 & $0.97(0.95-0.99)$ & 0.001 \\
\hline Current age (years) & $0.95(0.92-0.97)$ & $<0.001$ & $0.95(0.92-0.97)$ & $<0.001$ \\
\hline \multicolumn{5}{|l|}{ Tumor size } \\
\hline Up to $2 \mathrm{~cm}$ in diameter & 1.00 & - & 1.00 & - \\
\hline Between 2 and $5 \mathrm{~cm}$ in diameter & $2.31(1.08-4.93)$ & 0.031 & $1.70(1.03-2.81)$ & 0.038 \\
\hline Over $5 \mathrm{~cm}$ in diameter & $6.61(2.69-16.3)$ & $<0.001$ & $4.08(2.10-7.96)$ & $<0.001$ \\
\hline Any tumor size with chest wall or skin invasion & $9.56(4.13-22.2)$ & $<0.001$ & $6.55(3.58-11.9)$ & $<0.001$ \\
\hline \multicolumn{5}{|l|}{ Histologic grade } \\
\hline GI/G II & 1.00 & - & 1.00 & - \\
\hline G III & $3.27(1.85-5.78)$ & $<0.001$ & $2.11(1.41-3.17)$ & $<0.001$ \\
\hline \multicolumn{5}{|l|}{ Lymph nodes } \\
\hline Lymph node metastasis (S) & $6.81(3.63-12.8)$ & $<0.001$ & $3.67(2.43-5.55)$ & $<0.001$ \\
\hline No lymph node metastasis & 1.00 & - & 1.00 & - \\
\hline \multicolumn{5}{|l|}{ Type of surgery } \\
\hline Quadrantectomy & 1.00 & - & 1.00 & - \\
\hline Mastectomy & $2.06(1.19-3.57)$ & 0.010 & $1.67(1.10-2.53)$ & 0.015 \\
\hline Skin invasion & $5.38(2.76-10.5)$ & $<0.001$ & $4.87(2.83-8.36)$ & $<0.001$ \\
\hline Nipple invasion & $5.11(2.29-11.4)$ & $<0.001$ & $4.49(2.33-8.68)$ & $<0.001$ \\
\hline Multinodular & $1.97(1.01-3.83)$ & 0.047 & $1.39(0.80-2.42)$ & 0.242 \\
\hline Presence of carcinomas in situ & $1.16(0.66-2.01)$ & 0.608 & $1.17(0.78-1.76)$ & 0.456 \\
\hline Tumor-free surgical margin & $0.65(0.34-1.25)$ & 0.199 & $0.84(0.54-1.32)$ & 0.449 \\
\hline Presence of inflammatory infiltrate & $1.17(0.66-2.06)$ & 0.590 & $1.29(0.86-1.96)$ & 0.221 \\
\hline Estrogen receptor & $0.99(0.98-0.99)$ & $<0.001$ & $0.99(0.99-1.00)$ & 0.001 \\
\hline Progesterone receptor & $0.98(0.97-0.99)$ & $<0.001$ & $0.99(0.99-1.00)$ & 0.011 \\
\hline HER2 $>30 \%$ & $1.37(0.64-2.91)$ & 0.417 & $1.20(0.67-2.16)$ & 0.535 \\
\hline $\mathrm{Ki}-67$ & $1.03(1.02-1.04)$ & $<0.001$ & $1.02(1.01-1.03)$ & $<0.001$ \\
\hline \multicolumn{5}{|l|}{ Molecular classification } \\
\hline Luminal A & 1.00 & - & 1.00 & - \\
\hline Luminal B & $3.23(1.54-6.79)$ & 0.002 & $2.01(1.23-3.26)$ & 0.005 \\
\hline HER2 & $3.12(1.26-7.76)$ & 0.014 & $1.80(0.95-3.43)$ & 0.073 \\
\hline Triple negative & $5.37(2.41-11.9)$ & $<0.001$ & $2.26(1.24-4.13)$ & 0.008 \\
\hline
\end{tabular}

95\% Cl: 95\% confidence interval; HER2: human epidermal growth factor receptor type 2. 
disease-free survival rates by 6.61 and 4.08 times, respectively, when compared to tumors smaller than $2 \mathrm{~cm}$. Regarding T4 tumors, according to the univariate analysis, these tumors can worsen the overall and disease-free survival rates by 9.56 and 6.55 times, respectively. One fact that reinforces this statement is that skin invasion represented an increase of 5.38 times in the death rate and 4.87 times in the possibility of recurrence. Likewise, as T4 tumors, nipple invasion had a slightly more modest probability, with an increase in the possibility of death by 5.11 times and in the possibility of recurrence by 4.49 times. Tumor size compromises the favorable prognosis in larger lesions $(>2 \mathrm{~cm})$, mainly due to the impairment of more than $70 \%$ of the local lymphatic system ${ }^{10,26,27}$.

The $1 \%$ increase in Ki-67 values raises, on average, by $2 \%$ and $1 \%$ the risk of death and recurrence, respectively. This factor is inversely proportional to the survival of patients with breast can$\mathrm{cer}^{21}$. The increase in Ki-67 is not only related to the proliferation of tumor cells, but also to the proliferation of blood vessels key to tumor growth and the metastasis process, since a neoplasm would not exceed 2-3 mm without a minimally adequate vascular network ${ }^{10,28}$. Tumor cell proliferation is related to prognosis in many tumors. The recognized aggressiveness of tumors classified as luminal $\mathrm{B}$, when compared to luminal A ones, is probably related to Ki-67. It consists of a nuclear antigen present in the active phases of the entire cell cycle, with the exception of the G0 phase (resting phase). Although Ki-67 is essentially recognized for determining prognosis, it cannot be used as a basic criterion, since breast cancer is related to many factors that, together, determine the prognosis of each patient ${ }^{20}$.
Only tumors classified as histologic grade III presented significant values of death or recurrence, accounting for 3.27 and 2.11 times, respectively, which occurs due to the ease of induction to post-chemotherapy cell apoptosis in breast cancer cells of histologic grades I and $\mathrm{II}^{29}$.

According to the univariate analysis, the presence of lymph node metastasis increases death probability by 6.81 times and the risk of recurrence by 3.67 times.

Death probability was only statistically higher in triple-negative tumors, with a probability 5.37 times higher for death and 2.26 times higher for recurrence in patients within this classification. Although the triple-negative tumor, in many cases, presents a complete pathological response, this does not translate into better survival ${ }^{20}$. This finding corroborates the statement that triple-negative breast cancer has the worst prognosis, with disease-free survival between 14 and 17.8 months. Its guarded prognosis is closely related to the fact that this grade of breast neoplasia has no specific target therapy ${ }^{30}$.

The luminal B subtype represented the second-worst prognosis in the univariate analysis, with a 3.23 times higher probability of death and a 2.01 times higher probability of recurrence when compared with luminal A - data that negatively outweigh even HER2 tumors, which presented overall survival 3.12 times worse and disease-free survival 1.80 times worse when compared to luminal A. The prognosis of HER2 tumors was better when compared to luminal $\mathrm{B}$. This fact may be related to the treatment provided to HER2 patients, since HER2 tumors demonstrate

Table 3. Multivariate Cox regression analysis to evaluate factors associated with overall survival and disease-free survival.

\begin{tabular}{|c|c|c|c|c|}
\hline \multirow{2}{*}{ Variables } & \multicolumn{2}{|c|}{ Overall survival } & \multicolumn{2}{|c|}{ Disease-free survival } \\
\hline & Hazard ratio $(95 \% \mathrm{Cl})$ & $\mathbf{P}$ & Hazard ratio $(95 \% \mathrm{Cl})$ & $\mathbf{P}$ \\
\hline Current age (years) & $0.96(0.94-0.98)$ & $<0.001$ & $0.96(0.95-0.98)$ & $<0.001$ \\
\hline \multicolumn{5}{|l|}{ Tumor size } \\
\hline Up to $2 \mathrm{~cm}$ in diameter & 1.00 & - & 1.00 & - \\
\hline Between 2 and $5 \mathrm{~cm}$ in diameter & $1.21(0.54-2.69)$ & 0.642 & $1.25(0.74-2.10)$ & 0.410 \\
\hline Over $5 \mathrm{~cm}$ in diameter & $3.40(1.32-8.75)$ & 0.011 & $3.09(1.53-6.23)$ & 0.002 \\
\hline Any tumor size with chest wall or skin invasion & $3.56(1.41-8.99)$ & 0.007 & $4.34(2.25-8.36)$ & $<0.001$ \\
\hline \multicolumn{5}{|l|}{ Lymph nodes } \\
\hline Lymph node metastasis (S) & $4.11(2.06-8.21)$ & $<0.001$ & $2.58(1.64-4.08)$ & $<0.001$ \\
\hline No lymph node metastasis & 1.00 & - & 1.00 & - \\
\hline Progesterone receptor & $0.99(0.98-1.00)$ & 0.043 & - & - \\
\hline $\mathrm{Ki}-67$ & $1.02(1.01-1.03)$ & 0.002 & $1.01(1.00-1.02)$ & 0.008 \\
\hline \multicolumn{5}{|l|}{ Molecular classification } \\
\hline Luminal A & 1.00 & & 1.00 & \\
\hline Luminal B & $0.90(0.40-2.02)$ & 0.793 & $0.81(0.45-1.45)$ & 0.478 \\
\hline HER2 & $1.20(0.44-3.25)$ & 0.722 & $1.06(0.53-2.13)$ & 0.865 \\
\hline Triple negative & $1.24(0.44-3.47)$ & 0.679 & $1.08(0.50-2.33)$ & 0.843 \\
\hline
\end{tabular}

95\%Cl: 95\% confidence interval; HER2: human epidermal growth factor receptor type 2. 
more satisfactory results when aggressive neoadjuvant treatments are administered, which benefit patients classified with this type of breast cancer ${ }^{29}$.

Luminal A classification accounted for the best prognosis, which is probably related to the presence of the progesterone receptor. This receptor presented a positive relationship with a better prognosis, proving to be an independently associated factor, and its increase reduced the risk of death by $1 \%$. This corroborates the results of recent studies whose authors report the association of prognoses significantly favorable to tumors with positive estrogen receptors ${ }^{10,28,30}$.

In the multivariate analysis, no statistical relevance was found in the molecular classification.

Moreover, in this analysis, the one-year increase in age reduces the probability of death or recurrence, on average, by $4 \%$. Death within a 10-year period is directly related to the presence of two factors: lymph node involvement and the age group of 60 years old or older9.

Tumors of more than $5 \mathrm{~cm}$ in diameter and classified as T3, when analyzed in the multivariate analysis, increase the risk of death or recurrence by 3.5 times.

According to the same analysis, the presence of metastasis in lymph nodes increases the risk of death and recurrence by 4.78 and 2.63 times, respectively, differing from what is reported in the literature ${ }^{10}$.

\section{CONCLUSION}

According to the molecular classification, among the predictive factors, the triple-negative tumor has the worst overall survival and the highest risk of recurrence, and luminal A classification presents the best survival. The increased presence of Ki-67 proved to be a reference factor for worse prognosis. Luminal B molecular classification accounted for the second worst prognosis, surpassing HER2 tumors. Among prognostic factors, tumor size, lymph node metastasis, and skin invasion were deemed reference factors for worse prognosis and lower overall and disease-free survival rates. Further studies and investigation of new markers are required in order to contribute to determining even more reliable prognoses.

\section{AUTHORS' CONTRIBUTION}

D. D.: Conceptualization, Data curation, Formal analysis, Funding acquisition, Investigation, Methodology, Project administration, Solfwares, Visualization, Writing - original draft, Writing review and editing.

C. Z.: Conceptualization, Investigation, Methodology, Project administration, Resources, Validation, Supervision, Writing review and editing.

\section{REFERENCES}

1. Instituto Nacional de Câncer José Alencar Gomes daSilva. Estatísticas do câncer [Internet]. Rio de Janeiro: INCA; 2019 [acessado em 15 jan. 2019]. Disponível em: https://www.inca.gov.br/numeros-de-cancer

2. Stewart BW, Wild CP. World Cancer Report. 2014. v. 3. p. 16-54.

3. Tavassoli FA. Challenges in breast pathology: new twists on old problems. Arch Pathol Lab Med. 2009;133(6):852-4. https:// doi.org/10.1043/1543-2165-133.6.852

4. Zaha DC. Significance of immunohistochemistry in breast cancer. World J Clin Oncol. 2014;5(3):382-92. https://dx.doi. org/10.5306\%2Fwjco.v5.i3.382

5. Freitas Junior R, Nunes RD, Martins E, Curado MP, Freitas NAMA, Soares LR, et al. Fatores prognósticos do câncer de mama e sobrevida global em cinco e dez anos na cidade de Goiânia, Brasil: estudo de base populacional. Rev Col Bras Cir. 2017;44(5):435-43. http://dx.doi.org/10.1590/0100-69912017005003

6. Anderson WF, Jatoi I, Devesa SS. Distinct breast cancer incidence and prognostic patterns in the NCI's SEER program: suggesting a possible link between etiology and outcome. Breast Cancer Res Treat. 2005;90(2):127-37.https://doi.org/10.1007/s10549-004-3777-3

7. Dutra MC, Rezende MA, Andrade VP, Soares FA, Ribeiro MV, Paula EC, et al. Imunofenótipo e evolução do câncer de mama: entre mulheres muito jovens e mulheres na pós-menopausa. Rev Bras Ginecol Obstet. 2009;31(2):54-60. http://dx.doi. org/10.1590/S0100-72032009000200002
8. Aquino RGF, Pinheiro LGP, Ferreira MVP, Cavalcanti DIM, Oliveira ALS, Gomes NN, et al. Ductal carcinoma of the breast: morphological aspects according to the age. J Bras Patol Med Lab. 2015;51(4):252-7. http://dx.doi.org/10.5935/16762444.20150042

9. Ayala ALM, Anjos JC, Cassol GA, Höfelmann DA. Sobrevida em 10 anos em mulheres com câncer de mama: coorte história de 2000-2014. Ciênc Saúde Coletiva. 2019;24(4):1537-50. http://dx.doi.org/10.1590/141381232018244.16722017

10. Agarwal S, Singh A, Bagga PK. Immunohistochemical evaluation of lymphovascular invasion in carcinoma breast with CD34 and D2-40 and its correlation with other prognostic markers. Indian J Pathol Microbiol. 2018;61(1):39-44. https:// doi.org/10.4103/IJPM.IJPM_791_16

11. Oliveira Filho HR, Dória MT, Piato JRM, Soares Junior JM, Filassi JR, Baracat EC, et al. Criteria for prediction of metastatic axillary lymph nodes in early-stage breast cancer. Rev Bras Ginecol Obstet. 2015;37(7):308-13. http://dx.doi.org/10.1590/ S0100-720320150005343

12. Tabar L, Vitak B, Chen HH, Duffy SW, Yen MF, Chiang CF, et al. The Swedish Two-county trial twenty years later. Updated mortality results and new insights from long-term followup. Radiol Clin North Am. 2000;38(4):625-51. https://doi. org/10.1016/s0033-8389(05)70191-3 
13. Perou CM, Sorlie MB, Eisen MB, Rijn MV, Jeffrey SS, Rees CA, et al. Molecular portraits of human breast tumours. Nature. 2000;406(6797):747-52. https://doi.org/10.1038/35021093

14. Ricci MD, Junqueira PAA. Marcadores moleculares em câncer de mama preditivos de metástases axilares. Rev Assoc Med Bras. 2008;54(3):189-201. http://dx.doi.org/10.1590/S010442302008000300001

15. Aquino RGF, Vasques PHD, Cavalcante DIM, Oliveira ALS, Oliveira BMK, Pinheiro LGP. Carcinoma ductal invasor: relação de características anatomopatológicas com a presença de metástases axilares em 220 casos. Rev Col Bras Cir. 2017;44(2):163-70. http://dx.doi.org/10.1590/010069912017002010

16. Hwang KT, Kim YA, Kim J, Chu AJ, Chang JH, Oh SW, et al. The influences of peritumoral lymphatic invasion and vascular invasion on the survival and recurrence according to the molecular subtypes of breast cancer. Breast Cancer Res Treat. 2017;163(1):71-82. https://doi.org/10.1007/s10549-017-4153-4

17. Buitrago F, Uemura G, Sena MCF. Fatores prognósticos em câncer de mama. Com Ciências Saúde. 2011;22(Supl. 1):S69-82.

18. Cheang MC, Chia SK, Voduc D, Gao D, Leung S, Snider J, et al. Ki-67 Index, HER2 status, and prognosis of patients with luminal B breast cancer. J Natl Cancer Inst. 2009;101(10):73650. https://doi.org/10.1093/jnci/djp082

19. Shen S, Wu G, Xiao G, Du R, Hu N, Xia X, et al. Prediction model of lymphovascular invasion based on clinicopathological factors in Chinese patients with invasive breast cancer. Medicine. 2018;97(43):e12973. https://doi.org/10.1097/ MD.0000000000012973

20. Wang RX, Chen S, Huang L, Shao ZM. Predictive value and prognosis of matrix metalloproteinase MMP -9 in neoadjuvant chemotherapy for patients with triplenegative breast cancer. BMC Cancer. 2018;18:1-8. https://doi. org/10.1186/s12885-018-4822-7

21. Marwah N, Batra A, Marwah S, Gupta V, Shakya S, Sen R. Correlation ofproliferativeindexwith various clinicopathologic prognostic parameters in primary breast carcinoma: A study from North India. J Cancer Res Ther. 2018;14(3):537-42. https:// doi.org/10.4103/0973-1482.167614
22. Elston CW, Ellis IO. Pathological prognostic factors in breast cancer. The value of histological grade in breast cancer: experience from a large study with long-term follow-up. Histopathology. 2002;41(3A):154-61.

23. Bhatti ABH, Jamshed A, Khan A, Siddiqui N, Muzaffar N, Shah MA. Comparison between Early and Late Onset Breast Cancer in Pakistani Women Undergoing Breast Conservative Therapy: is There any Difference? Asian Pac J Cancer Prev. 2014;15(13):5331-6. https://doi.org/10.7314/ apjcp.2014.15.13.5331

24. Rosa LM, Radünz V. Taxa de sobrevida na mulher com câncer de mama: Estudo de Revisão. Texto Contexto Enferm. 2012;21(4):980-9.

25. Costa Neto OF, Castro RB, Oliveira CV, Feitosa TVN, Alves Junior JJ, Cavalcante FP, et al. Fatores preditivos de metástases axilares em pacientes com câncer de mama e biópsia de linfonodo sentinela positivo. Rev Col Bras Cir. 2017;44(4):391-6. http://dx.doi.org/10.1590/0100-69912017004014

26. Bujor IS, Cioca A, Ceausu RA, Veaceslav F, Nica C, Cîmpean AM, et al. Evaluation of Vascular Proliferation in Molecular Subtypes of Breast Cancer. In Vivo. 2018;32(1):79-83. https:// doi.org/10.21873/invivo.11207

27. Pluta P, Jesionek-Kupnicka D, Kubicka-Wolkowska J, Pluta A, Brzozowski K, Potemski P. SMaC protein expression as a potent favorable prognostic factor in locally advanced breast Cancer. Pol J Pathol. 2018;69(1):33-41. https://doi.org/10.5114/ pjp. 2018.75334

28. Jafarian A,TasbandiA, GilanH,SheikhiM,RoshanN.Evaluation of CD30/CD4/CD8 in triple-negative invasive ductal carcinoma of breast in association with clinicopathological prognostic factors. Indian J Pathol Microbiol. 2018;61(4):500-4. https://doi. org/10.4103/IJPM.IJPM_67_18

29. Cheang MCU, Rijn MVD, Nielsen TO. Gene expression. Profiling of breast cancer. Annu Rev Pathol. 2008;3:67-97. https://doi.org/10.1146/annurev.pathmechdis.3.121806.151505

30. Kraby MR, Valla M, Opdahl S, Haugen OA, Sawicka JE, Engstrom MJ, et al. The prognostic value of androgen receptors in breast cancer subtypes. Breast Cancer Res Treat. 2018;172(2):283-96. https://doi.org/10.1007/s10549-018-4904-x 